\title{
Performance of suspension bridge hangers exposed to hazardous material fires considering wind effects
}

\author{
Qiling Zou, Kavi Pool and Suren Chen *i]
}

\author{
* Correspondence: suren.chen@ \\ colostate.edu \\ Department of Civil and \\ Environmental Eng., Colorado State \\ University, Fort Collins, CO 80523, \\ USA
}

\begin{abstract}
Traffic accidents involving vehicles transporting hazardous materials (HazMat) can cause serious fire hazards, threatening the safety of bridge infrastructure as well as nearby traffic. For critical bridges such as long-span cable-stayed and suspension bridges, fire hazards can not only cause severe structural damage, but also serious traffic disruption, congestion, and accidents. Unlike short-span bridges, long-span cable-supported bridges often experience considerable wind effects at the height of the bridge deck which can significantly influence fire hazards. As the critical components of cable-supported bridges, the failure of cables or hangers due to fire may trigger progressive failure of the bridge structure. Existing studies on fire simulation of long-span bridges, however, are very limited. Typical fire hazard scenarios from vehicles transporting hazardous material (HazMat) are simulated with fire dynamics simulation (FDS) software on a suspension bridge with a focus on the threats to hangers. To more realistically consider the potential fire hazards to bridge hangers of long-span bridges, appropriate fuel size, transverse offset distance, and wind effects are considered. The study of a baseline scenario is carried out first and followed by parametric studies to investigate the effects of wind speeds, longitudinal offsets, hazardous material types and spill sizes on the fire simulation results.
\end{abstract}

Keywords: Hazardous material, Suspension bridge, Long-span bridge, Fire, Wind

\section{Introduction}

On average, 100-300 vehicle crashes result in bridge fires in the United States every year according to Wright et al. (2013). More critical than crashes involving passenger vehicles, those involving vehicles transporting hazardous materials (HazMat) can cause serious fire hazards, threatening the safety of bridge infrastructure and also nearby traffic. For some critical bridges, including long-span cable-stayed and suspension bridges, structural damage or failure does not only mean the huge amount of direct repair cost of the structures, but also, sometimes more significant monetary costs associated with traffic disruption and rerouting. Compared to bridges with shorter spans, fire hazards on the long-span cable-supported bridges, such as cable-stayed and suspension bridges, have only received limited attention (e.g., Gong and Agrawal 2014; Chen et al. 2018).

(c) The Author(s). 2020 Open Access This article is licensed under a Creative Commons Attribution 4.0 International License, which permits use, sharing, adaptation, distribution and reproduction in any medium or format, as long as you give appropriate credit to the original author(s) and the source, provide a link to the Creative Commons licence, and indicate if changes were made. The images or other third party material in this article are included in the article's Creative Commons licence, unless indicated otherwise in a credit line to the material. If material is not included in the article's Creative Commons licence and your intended use is not permitted by statutory regulation or exceeds the permitted use, you will need to obtain permission directly from the copyright holder. To view a copy of this licence, visit http://creativecommons.org/licenses/by/4.0/. 
There has been very little field data, or even experimental data associated with fire hazards on long-span bridges. As a result, computational simulation serves as the primary way to examine fire threats to these bridges. In order to study fire hazards caused by vehicles transporting hazardous material on long-span bridges, one key step is to realistically simulate the fire scenario, providing some key data such as time-dependent temperatures of exposed structural elements.

Although performance-based standards are lacking in bridge design to resist fires, some case studies have been performed to investigate the process of fire related bridge failure. For example, the failure of the MacAurthur Maze overpass bridge (interchange of I-80, I-580, and I-880) in Oakland, CA was analyzed by Quiel et al. (2015a, 2015b). The researchers created a computationally efficient heat transfer model and estimated the failure of steel by correlating the loss of yield strength in steel to increasing temperature. In their study (Quiel et al. 2015a, 2015b), the authors were able to predict the time and location of failure of steel girder supporting the bridge. Fire dynamics simulator (FDS) is popular software developed by a team of researchers working with the National Institute of Standards and Technology (NIST) and VTT Technical Research Center of Finland. During the past decade, FDS has been used to simulate fire scenarios including on both buildings and also bridges. For example, Alós-Moya et al. (Alos-Moya et al. 2014) performed a case study of the I-65 overpass collapse using FDS to determine the time temperature profiles for the main steel girders beneath the overpass. Their process involved specifying a heat release rate per unit area (HRRPUA) for the tanker and the spill region, creating an adiabatic surface (a fictitious surface which cannot absorb or emit heat), and obtaining the temperatures on different points on the girder and deck along the length of the bridge. Temperature data was then applied to a finite element model of a steel girder to investigate the response of the bridge structure.

In comparison to fire simulations on short-span bridges, there have been very limited experimental and numerical studies on long-span bridges. Bennetts and Moinuddin (2009) explored the vulnerability of cable-stayed bridges to fuel tanker fires using a thermodynamics model that calculates the heat transfer via radiation and conduction through layers of insulation and cables from external to internal layers. They found tanker fires and LPG fire scenarios to be the most dangerous while admitting the LPG scenario, which involved flame jet incidence on a cable, was highly unlikely. Quiel et al. (2015b) simulated the effects of open-air hydrocarbon pool fires on a cable-stayed bridge. Sloane (2017) proposed some fire modeling techniques for studying fire effects on suspension bridge main cable. The most related experimental work is conducted by Chen et al. (2018) in which they investigated combustion characteristics of steel cable for cable-stayed bridge with a series of experiments. It was found that bridge fire incidents, especially for long-span cable stayed or suspension bridges, although being identified as one of the major causes of bridge collapses, are still an under-researched and under-codified area (Chen et al. 2018; Quiel et al. 2015a; Sloane 2017). In this study, typical fire hazard scenarios from HazMat vehicles are simulated with FDS on a suspension bridge with a focus on the threats to hangers. Because wind can play a significant role in HazMat fire propagation while considerable wind prevails at the height of bridge deck of a long-span bridge (typically over $50 \mathrm{~m}$ high), wind effect on the fire simulation is specifically considered. In addition to a baseline scenario, detailed 
comparative studies are conducted to investigate the effects from longitudinal offset of fire source, hazardous material source, wind speed and size of spill.

\section{Baseline fire scenario of HazMat tanker crashes}

In order to develop reasonable fire scenario of HazMat tanker crashes on bridges, some key simulation parameters critical to long-span bridges are discussed in the following.

\subsection{Fire type}

When a tanker crashes and catches fire on a bridge there are two possible fire scenarios. The tanker may quickly explode releasing all the thermal energy in an intense burst or the tanker will spill fuel onto the bridge deck which ignites and creates a pool fire. The pool fire will burn more steadily and over a much greater period of time than a catastrophic explosion scenario. Because of the longer duration of the pool fires the latter scenario poses a greater threat to hangers supporting the bridge deck as corroborated by Bennetts and Moinuddin (2009). Thus the present study focuses on pool fire scenarios with a volume reasonably expected from a tanker truck spill.

\subsection{Fuel amount in the fire simulation}

A fuel tanker typically carries approximately $34 \mathrm{~m}^{3}$ of fuel, such as gasoline. Depending on the nature of the accident and fuel spill, the amount of fuel consumed in the fire simulation can vary up to the total fuel volume. Some test simulations of different pool fire scenarios in FDS suggest that fire duration and heat release required to cause serious structural damage are achievable with far less than $34 \mathrm{~m}^{3}$ of gasoline. Therefore, a wide range of fuel amount up to $34 \mathrm{~m}^{3}$ fuel can be realistically simulated.

\subsection{Unique characteristics associated with long-span bridges}

Unlike short or medium-span bridges, the flame height is less crucial for hangers on cable-stay and suspension bridges. This is because hangers connect to the bridge girder/deck such that a pool fire scenario can usually engulf the lower part of the hangers regardless of fire height. Because the crowning of the road will gather fuel towards the curb, the offset between curbs and cables is a more important parameter. HazMat trucks tend to drive in the outermost lane therefore the transverse offset between the fire and hangers is controlled by the transverse distance between the curb and hangers. For typical long-span bridges, considerable winds are common at the height of the bridge deck (more than $50 \mathrm{~m}$ above water or ground). These winds can greatly alter the flame trajectory such that the flames "bend" to engulf cables as well as exacerbating the combustion and heat release processes. The wind effect on fire on long-span bridges is very critical and unique as compared to bridges with shorter spans.

Based on all these considerations, a baseline simulation fire scenario for a typical suspension bridge is developed and the simulation domain in FDS is graphically shown in Fig. 1. Two vertical hangers are $6 \mathrm{~m}$ apart which represents a typical hanger spacing distance for suspension bridges. A concrete barrier exists between the driving lanes and the hangers with a $1 \mathrm{~m}$ interval. A rectangular shaped fuel spill is approximated with 3 $\mathrm{m}$ width and $5.4 \mathrm{~m}$ length to represent a typical fuel spill scenario. 


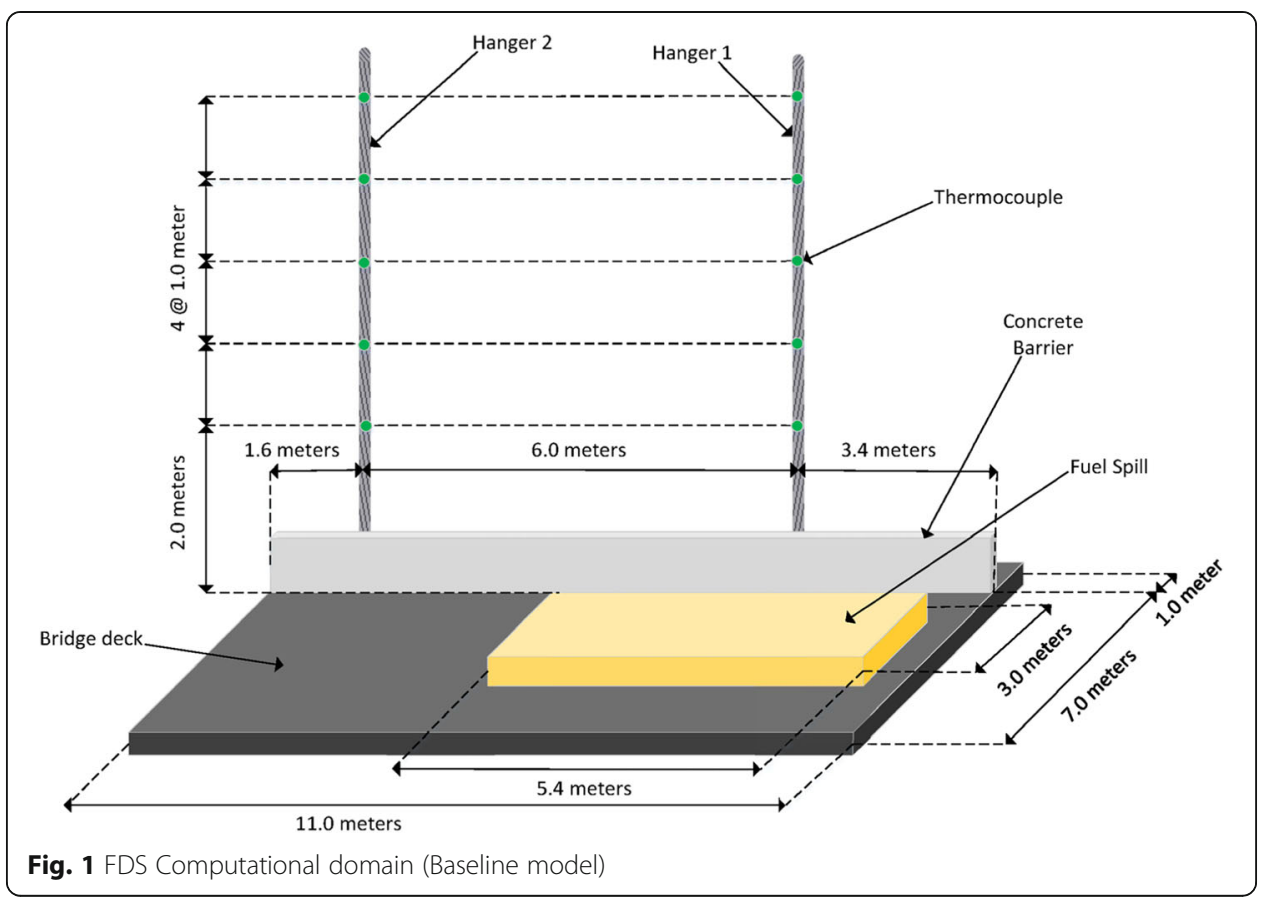

\section{FDS model development}

FDS requires the user to input all parameters as a text file to define the spatial and temporal bounds of the model, thermal properties, output data, and other parameters. As the model behaves to the real world scenario, the user can make further predictions and decisions with higher confidence. Figure 1 defines the FDS computational domain. Since hangers are the main study objectives in this study, five thermocouple sensors are assigned on each of two hangers with uniform intervals of $1 \mathrm{~m}$ (Fig. 1).

The model shown in Fig. 1 is first analyzed with a coarse mesh and then followed by simulations with a refined mesh. For larger simulations, the coarse mesh is composed of cubes $25 \mathrm{~cm}$ along each side. The mesh dimensions are cubic to avoid inaccurate results and numerical instabilities. The refined models are made of cubes with $20 \mathrm{~cm}$ on each side, and the cube size is selected based on a good compromise between accuracy and computational efficiency. It is generally accepted that when further discretization of the mesh does not significantly affect results, the model is "mesh-independent" and no further discretization of the mesh is required. It should be noted that although the cables appear to be rectangular in Fig. 2, the heat transfer calculations are based on a cylindrical object feature.

\subsection{Selection of simulation time period}

The test simulation is conducted with 20-min simulation time period, which is selected based on Eurocode. According to Eurocode (CEN 2005), hydrocarbon timetemperature curves can reach the peak temperature of $1000^{\circ} \mathrm{C}$ in about $20 \mathrm{~min}$. However, the test simulation results in this study suggest that the simulation critical elements (i.e. hangers) usually only reach slightly more than $500^{\circ} \mathrm{C}$ during this period of time. Such discrepancy is primarily due to the fact that Eurocode fire curves were 

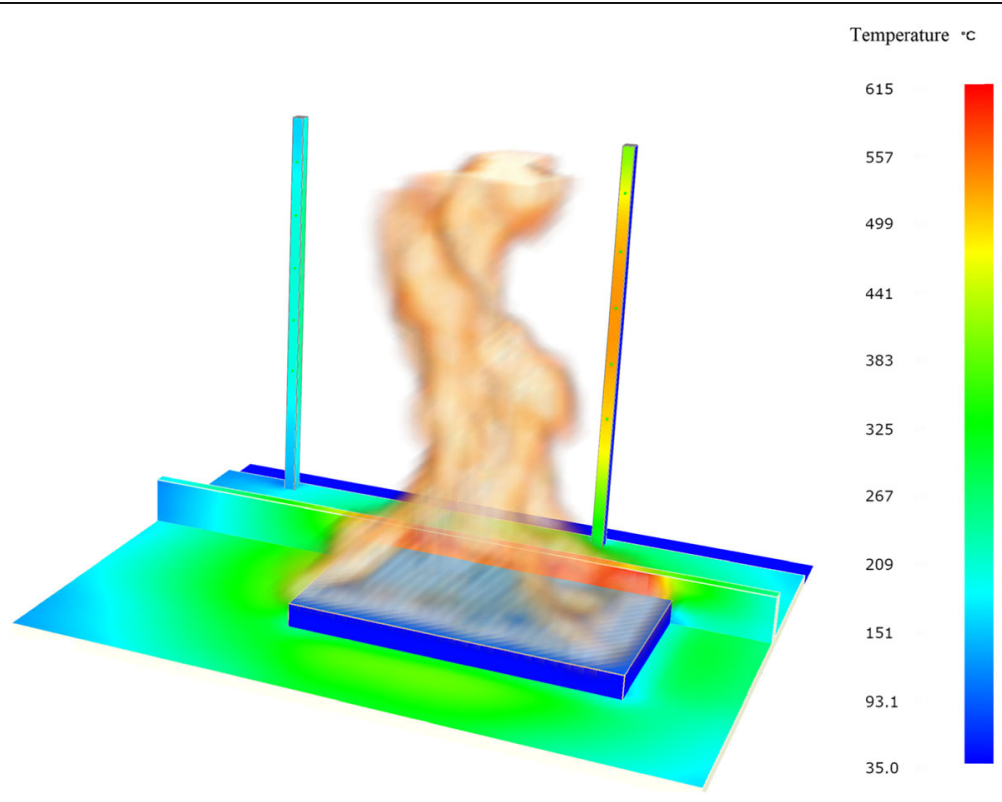

Fig. 2 FD simulation results of suspension bridge hangers

obtained based on interior fire instead of open fire and also possibly the conservative nature of the guidelines. In order to capture higher temperature on the bridge cables, the simulation time is selected as $40 \mathrm{~min}$ in the following models.

\subsection{Thermal properties}

It is crucial to input accurate thermal properties for all materials such that FDS can accurately simulate the "real" scenario. Most of the thermal properties used in simulation are obtained from various sources such as the online reference Engineering Toolbox ("Material properties" 2015) and FDS User Guide (McGrattan et al. 2015) and these values were checked against available references to insure accuracy. Table 1 lists the thermal properties of concrete and structural steel.

\subsection{Fuel}

The fuel used in experimentation is octane $\left(\mathrm{C}_{8} \mathrm{H}_{18}\right)$, one of the components of standard gasoline/petrol. Due to the restriction of only one gas phase reaction in FDS the exact fuel mixture could not be refined. Instead, the relative quantity of impurities in the gas are accounted for. For simulations it is assumed that the fuel contains $3 \%$ impurities by mass, as proposed in the FDS User Guide (McGrattan et al. 2015) for combustion of liquid ethanol, which is prevented from combusting by FDS during simulation. In order to provide more insights in terms of fuel species on the simulation results, two

Table 1 Thermal Properties of Concrete and Structural Steel

\begin{tabular}{lll}
\hline & Concrete & Structural steel \\
\hline Density $\left(\mathrm{kg} / \mathrm{m}^{3}\right)$ & 2400 & 7870 \\
Specific heat $(\mathrm{kJ} / \mathrm{kg} \cdot \mathrm{K})$ & 0.88 & 0.486 \\
Thermal conductivity $(\mathrm{W} / \mathrm{m} \cdot \mathrm{K})$ & 0.29 & 51.9 \\
\hline
\end{tabular}


additional species are also studied in this study: Toluene and Butane, both of which are primary components of gasoline. The thermal and combustive properties of gasoline surrogate are listed in Table 2.

\subsection{Temperature monitoring}

The FDS has a DEVC (device) function that allows the user to create points in the model space that record certain quantities (temperature, heat flux, mass flow etc.). To gain proper insight into the thermodynamic response of the cable, a set of virtual thermocouples were placed on the surface of the hanger, along the length of the hanger at $1 \mathrm{~m}$ increments, see Fig. 1. The adiabatic surface temperature records obtained from the FDS were then used as the time-dependent boundary conditions in the subsequent thermal analysis by Abaqus in order to compute the internal temperature distribution of the hanger (Alos-Moya et al. 2014). Currently it is still a challenge to realistically model the strand structure of a hanger; the hanger in the thermal analysis was modeled as a lumped mass with homogeneous heat transfer properties. Although the obtained internal temperature may not represent the actual temperature of real hangers, it can still provide some preliminary yet important observations which can help future studies (Sloane 2017).

\section{Simulation results}

\subsection{Temperature results}

Figure 3 illustrates temperature results of the baseline model used in this investigation. The baseline wind speed is $10 \mathrm{~m} / \mathrm{s}$, across the spill directly into the hanger. The thermocouples are placed vertically along the front face of the cable. The different lengths in the legend refer to the height of the respective thermocouple above the top of the fuel spill.

The interior temperature distribution within the hanger was yielded by the thermal analysis, as shown in Fig. 4. It can be seen that the temperature is not distributed uniformly over the cross section of the hanger; although all nodal temperatures increase over time, which is consistent with the trend of the exterior temperature, the side facing the fire has larger temperature than the side away from the fire due to the heat transfer. And the largest temperature difference can reach $300^{\circ} \mathrm{C}$ at $17 \mathrm{~min}$ as depicted in Fig. 4c. It should be noted that the actual hanger can be composed of multiple steel strands; this thermal simulation can provide approximate interior temperature each strand experienced within the cross section for more detailed analysis (Sloane 2017).

Table 2 Thermal and Combustive Properties - Gasoline surrogate (McGrattan et al. 2015)

\begin{tabular}{lc}
\hline Density $\left(\mathrm{kg} / \mathrm{m}^{3}\right)$ & 720 \\
\hline Specific heat $(\mathrm{kJ} / \mathrm{kg} \cdot \mathrm{K})$ & 2.131 \\
Thermal conductivity $(\mathrm{W} / \mathrm{m} \cdot \mathrm{K})$ & 0.15 \\
Emissivity (unitless) & 0.90 \\
Boiling temperature $\left({ }^{\circ} \mathrm{C}\right)$ & 125 \\
Heat of reaction $(\mathrm{kJ} / \mathrm{kg})$ & 837 \\
Heat of combustion $(\mathrm{kJ} / \mathrm{kg})$ & 43,700 \\
Absorption coefficient $\left(\mathrm{m}^{-1}\right)$ & 1534 \\
\hline
\end{tabular}




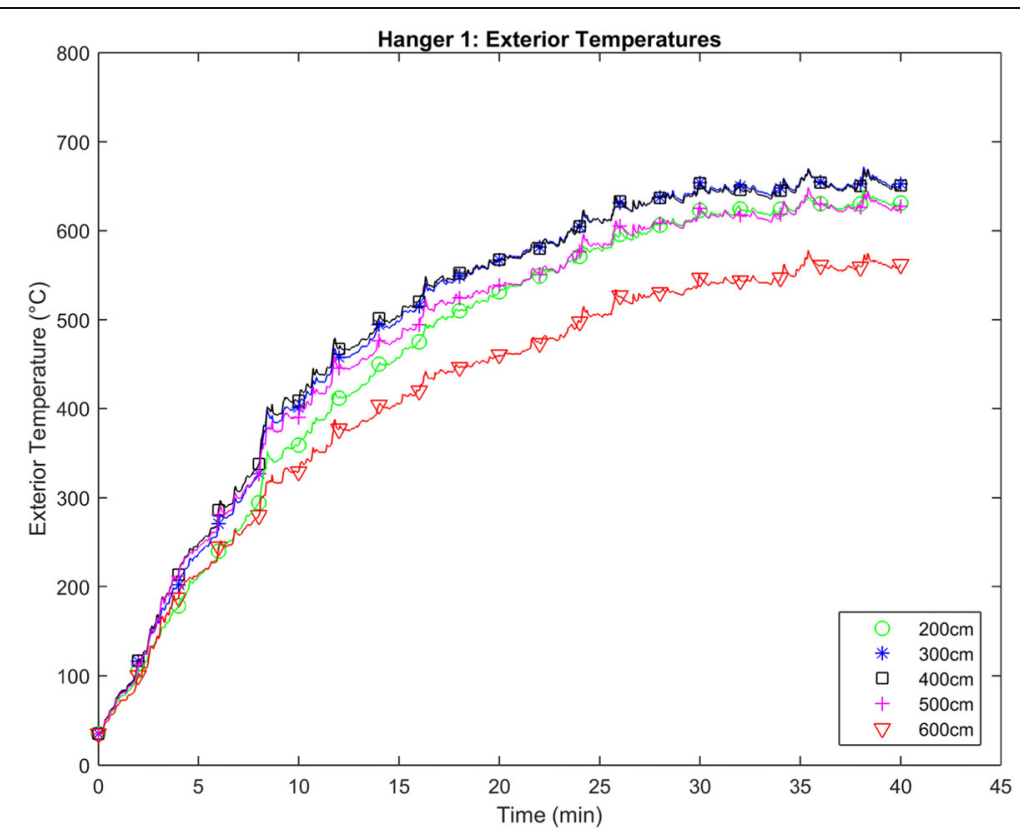

Fig. 3 Time histories of exterior temperature for the baseline case $(10 \mathrm{~m} / \mathrm{s}$ wind speed)

Figure 5 illustrates the time histories of average interior temperature of different cross section along the hanger.

FDS predicts the visible flames by examining the heat release rate per unit volume and specifying a borderline value above which visible flames are present. With this method, flames appear to reach the upper limit of the domain of models in Smokeview of FDS. Another popular method to predict flame height is Heskestad's equation for flame height. Woodworth et al. (2015) used it as a reference in their assessment of cable-stay bridge fire vulnerability. It states:

$$
L_{f}=0.235 \dot{Q}^{\frac{2}{5}}-1.02 D
$$

where:

$L_{f}=$ the height of visible flame $(\mathrm{m})$.

$\dot{Q}=$ the heat release rate of the fire $(\mathrm{kW})$.

$D=$ the diameter of the pool fire $(\mathrm{m})$.

Since the spill used in this study, and in real HazMat fire scenarios, is typically not circular an effective diameter is calculated using a circle of the same area with the Eq. (2) as shown below.

$$
D_{\text {eff }}=\sqrt{\frac{4 w l}{\pi}}
$$

where:

$D_{\text {eff }}=$ the effective diameter of the fuel spill (m).

$w=$ the width of the fuel spill (m).

$l=$ the length of the fuel spill $(\mathrm{m})$.

Using the effective diameter and heat release rate time history of the baseline study a flame height versus time plot is created and shown below in Fig. 6 . 


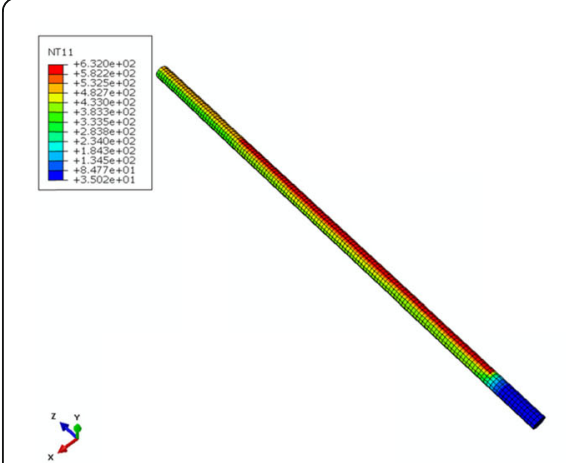

(a)

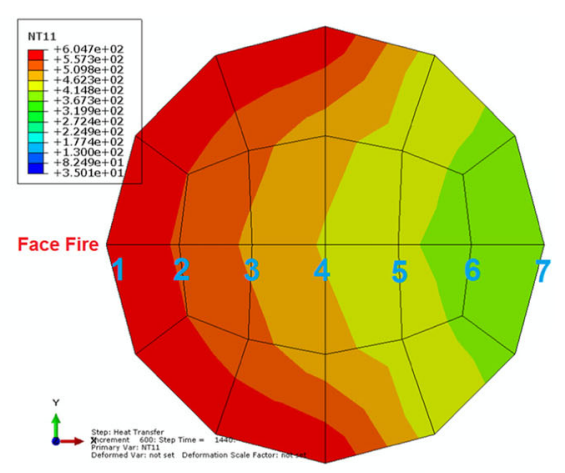

(b)

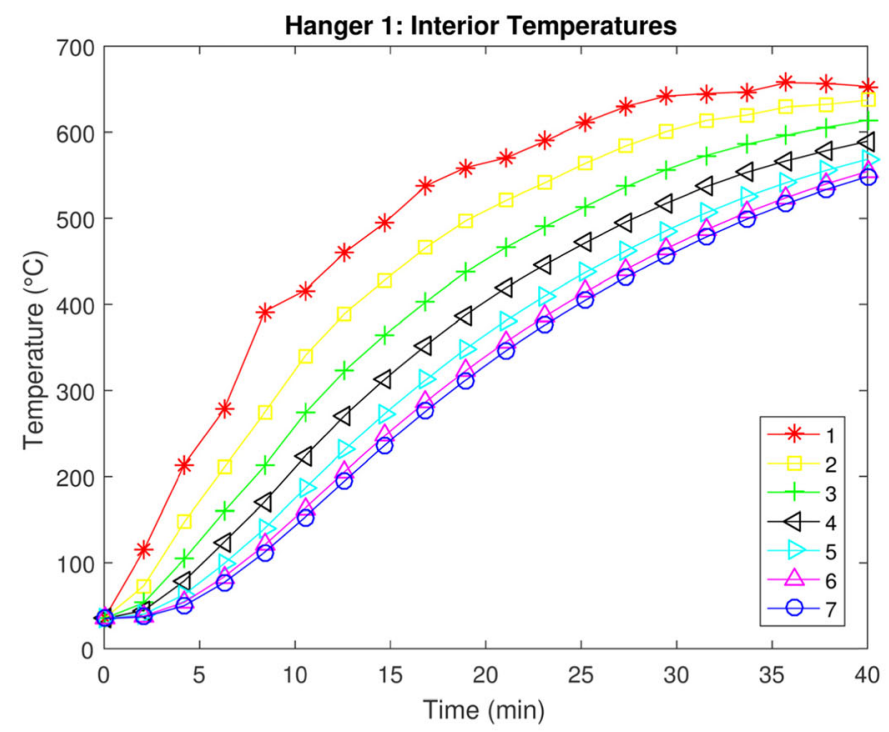

(c)

Fig. 4 The thermal analysis illustration for the baseline case: a the whole hanger model; $\mathbf{b}$ the internal temperature distribution over the cross section at height $300 \mathrm{~cm}$ at $24 \mathrm{~min} ; \mathbf{c}$ time histories of interior temperature of different nodes within the same cross section

The results in Smokeview are corroborated by these estimates. The upper limit of the domain is $7.4 \mathrm{~m}$ and flame height predicted by Hesketad's equation reaches about twice the domain limit. Even though flame heights reach outside of the model domain, the hottest hanger sections are within the model which is the focus of this investigation. Further increasing the simulation domain in FDS does not change this observation.

\subsection{Strength reduction estimation due to fire}

Instead of performing rigorous investigation into the thermo-mechanical response as some researchers have done using finite element software, this paper compares the percentage of remaining yield strength relative to temperature, following the work conducted by Quiel (2015a, 2015b). This method is based off fire safety guidelines given in Eurocode. Quiel determined that steel members had lost over $75 \%$ of their yield 


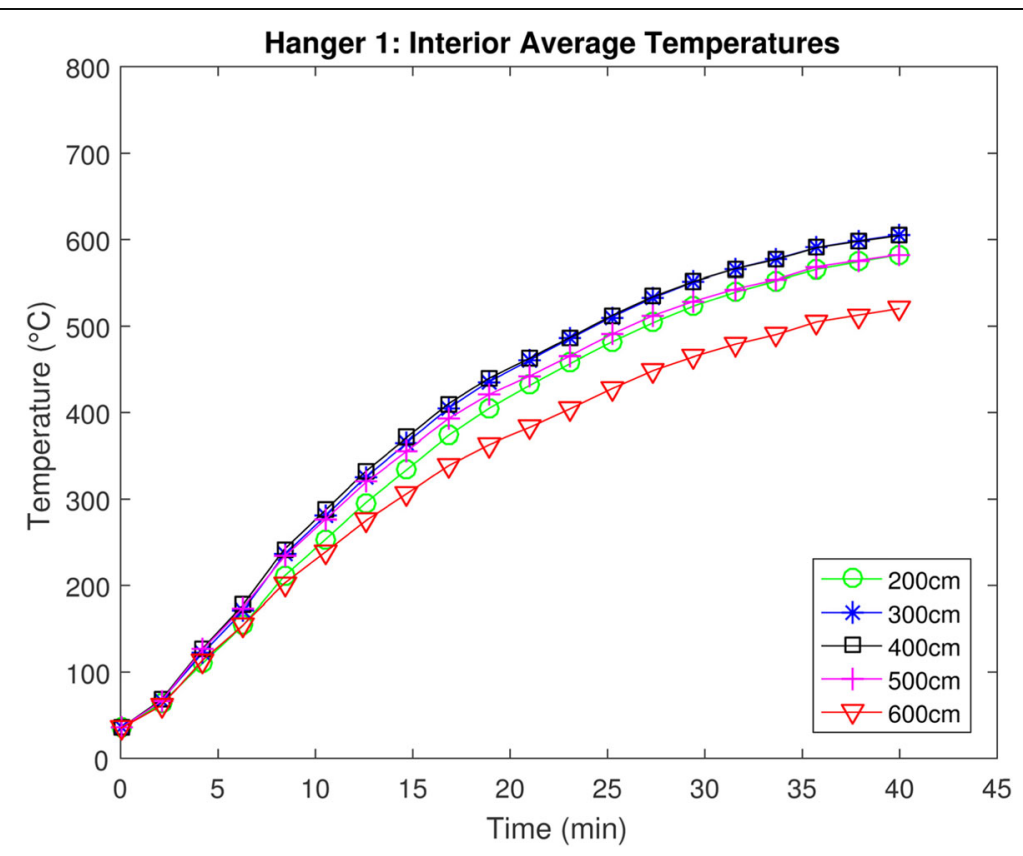

Fig. 5 Time histories of average interior temperature for the baseline case $(10 \mathrm{~m} / \mathrm{s}$ wind speed)

strength upon reaching about $400{ }^{\circ} \mathrm{C}$. High-temperature steel mechanical properties found by Wright et al. (2013) support Quiel's proposal to some extent (predicting 75\% strength loss around $600^{\circ} \mathrm{C}$ ). The ASCE guideline and Eurocode both have the models for predicting the yield strength of the steel under high temperature, which were adopted here to estimate the strength loss of the hanger as a function of time for the baseline case (Wright et al. 2013).

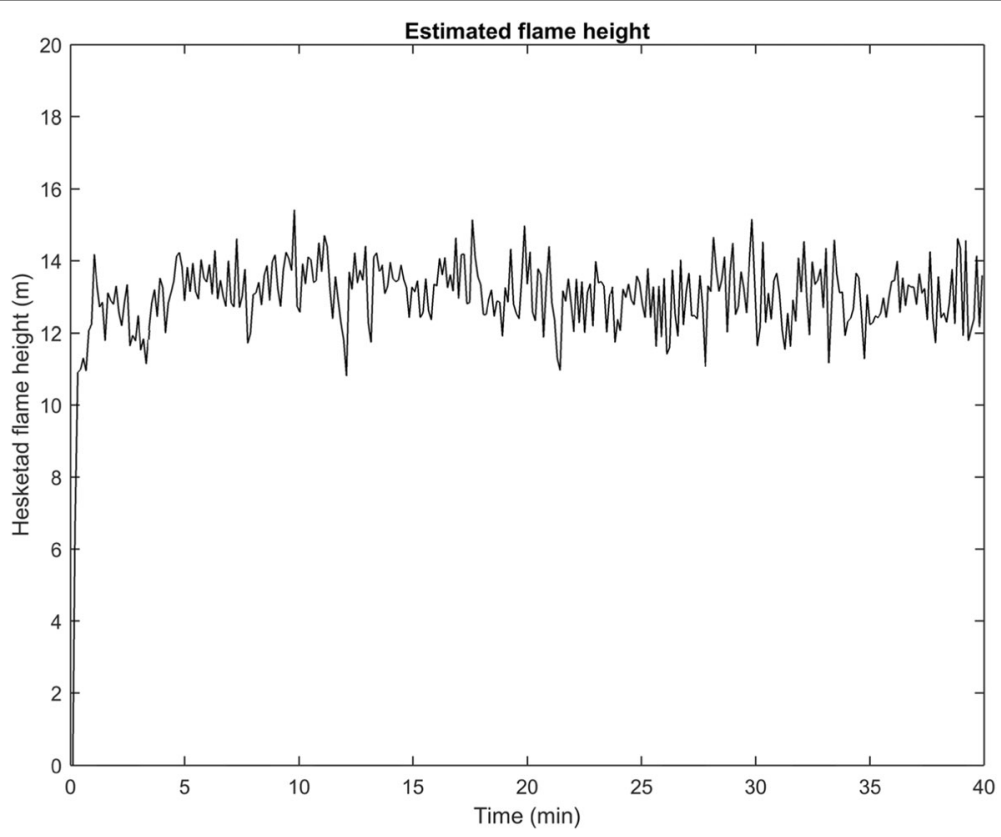

Fig. 6 Estimated flame height 
Based on the prediction models of relative yield strength of steel under different temperature specified in ASCE and Eurocode, the time history of average interior temperature in Fig. 5 are converted to estimates of remaining stress capacity and the results of the percentage of remaining strength for steel over time are plotted in Fig. 7. Interested readers are referred to Wright et al. (2013) for more details about the prediction models of relative yield strength of steel under different temperature. The $y$ axis in Fig. 7 denotes the ratio of the yield strength at a given temperature to the room temperature yield strength at $20^{\circ} \mathrm{C}$. The temperature profile used is the most critical and hottest section of Cable 1 in the baseline case. It can found that the ASCE model gives a more conservative strength loss prediction than the Eurocode. At the end of the simulation, the remaining strengths predicted by the ASCE and Eurocode are $37 \%$ and $48 \%$, respectively. Before more rigorous structural analysis considering the hanger's actual structural composition is carried out, the results provide approximated estimates of possible consequences due to heating of fire.

\section{Parametric studies}

In the previous section, the baseline fire scenario has been outlined. In order to look into the effects of several critical inputs, parametric studies are carried out in the following sections. Specifically, the parametric studies cover the effects of wind speeds, longitudinal offset distance, hazardous material surrogate species, and spill size on the simulation results.

\subsection{Effect of wind speed}

For the baseline scenario, wind speed of $10 \mathrm{~m} / \mathrm{s}$ was studied in previous sections. In order to examine the impacts from different wind conditions, FDS simulations with

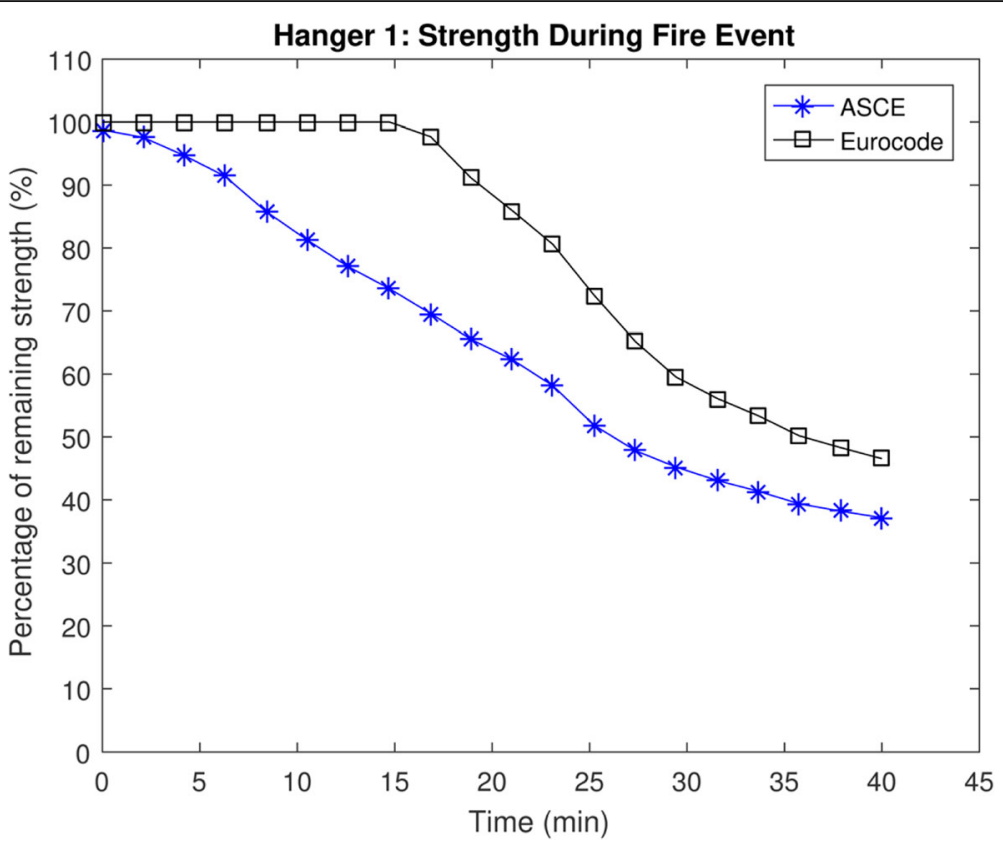

Fig. 7 Time histories of percentage of remaining strength for the baseline case $(10 \mathrm{~m} / \mathrm{s}$ wind speed) 
two other wind speeds, $5 \mathrm{~m} / \mathrm{s}$ and $15 \mathrm{~m} / \mathrm{s}$, are conducted and the results are shown in Fig. 8a and b, respectively. Fig. 8a gives the simulation results for a lower wind speed than the baseline wind speed, i.e., $5 \mathrm{~m} / \mathrm{s}$. FDS results suggest that the temperature increases most quickly at the beginning of the fire and begins to fall off towards the end of the simulation. The shapes of the curves suggest the temperature is approaching a horizontal asymptote, i.e. peak temperature. Cable 1, which is most directly exposed to the fire, reaches a temperature of $570{ }^{\circ} \mathrm{C}$ by the end of the simulation, after $40 \mathrm{~min}$. The height of the cable above the spill that achieves the highest temperature is located 400 $\mathrm{cm}$ above the fuel spill. This location would experience the greatest strength and stiffness reductions although the temperature curve is within $50^{\circ} \mathrm{C}$ for the region directly exposed to the fire, from $2 \mathrm{~m}$ to $6 \mathrm{~m}$ above the bridge deck. In the baseline study (wind speed is $10 \mathrm{~m} / \mathrm{s})$, the final temperature is about $100^{\circ} \mathrm{C}(18 \%)$ higher than that for the critical thermocouple at $400 \mathrm{~cm}$ above the spill. The difference in temperature between the hottest and coldest thermocouples is about $100^{\circ} \mathrm{C}$ for both wind speeds. Compared to the case with $5 \mathrm{~m} / \mathrm{s}$ wind speed, the baseline study also exhibits more fluctuation in its time temperature curve.

The next case with a higher wind speed of $15 \mathrm{~m} / \mathrm{s}$ as shown in Fig. 8b, maintains the trend noted previously, quicker temperature gains and more turbulence than Fig. 8a. Temperature increases are three to four times greater per unit increase in wind speed. This indicates that controlled combustion can be greatly sped up by the existence of wind. During severe wind events such increase could become even more drastic, which cannot be ignored for the risk assessment of structural members subjected to fire.

By picking the highest measurements of all thermocouples on Hanger 1 over time, Fig. 9 depicts the time histories of the peak exterior temperature and remaining strength under four different wind speeds (i.e. 0, 5, 10 and $15 \mathrm{~m} / \mathrm{s}$ ). In all these simulations, wind direction is assumed to be facing the cable, "pushing" the fire toward the hanger as the worst-case scenario. It is noted that wind not only "pushes" fire either away or toward the hanger, it also helps mix the fuel with oxygen and increases heat output regardless of direction. For lower wind speeds the maximum temperature does not exceed $600{ }^{\circ} \mathrm{C}$, while for the maximum wind speed like $15 \mathrm{~m} / \mathrm{s}$, the peak temperatures can exceed $1000^{\circ} \mathrm{C}$. Correspondingly, the percentage of remaining strength under $15 \mathrm{~m} / \mathrm{s}$ wind speed can drop to as low as $10 \%$, while those under lower wind speeds can

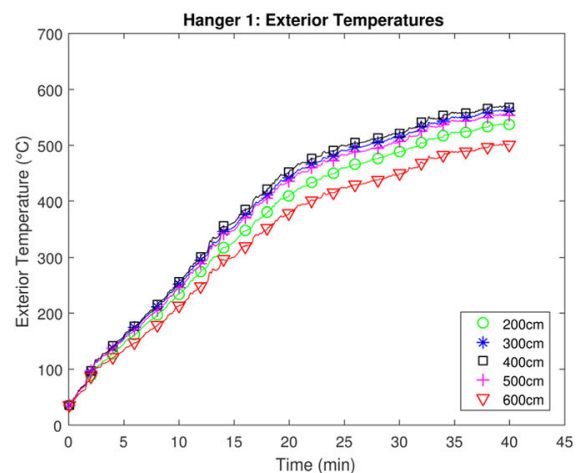

(a)

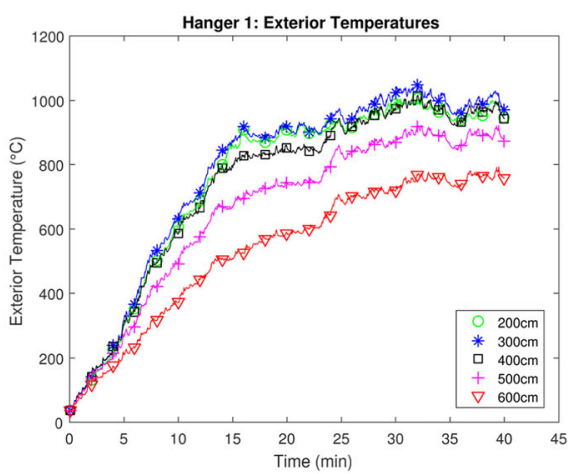

(b)

Fig. 8 Time histories of exterior temperature of Hanger 1: a $5 \mathrm{~m} / \mathrm{s}$ wind speed; $\mathbf{b} 15 \mathrm{~m} / \mathrm{s}$ wind speed 


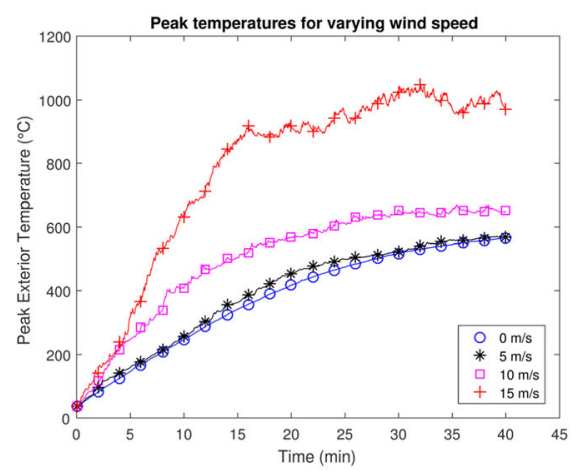

(a)

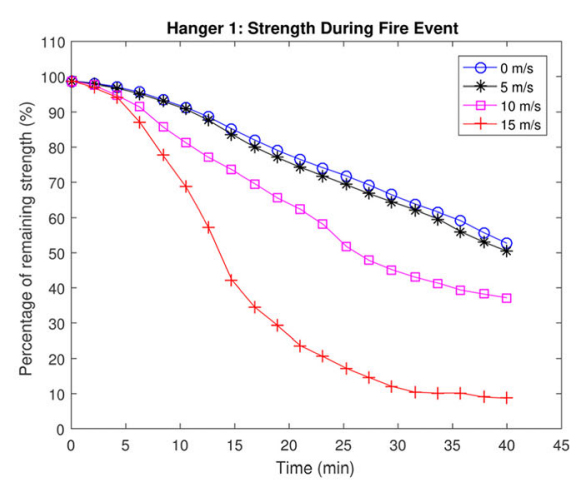

(b)

Fig. 9 Comparison of peak exterior temperatures and remaining strengths of the hanger under different wind speeds: a peak exterior temperature; $\mathbf{b}$ percentage of remaining strength based on ASCE code

retain $40 \%-50 \%$ of original strength at the end of the simulation. It is obvious that the peak temperature exhibits exponential increase over wind speeds, exacerbating the strength loss and highlighting the significance of including wind effects in the fire simulation on long-span bridges where strong wind is common as discussed earlier.

\subsection{Effect of longitudinal offset}

As discussed previously, the bridge geometry constrains typical lateral offsets between HazMat vehicle fires and hangers, but the longitudinal offset is more variable. Unless accidents are intentional, HazMat accidents can occur anywhere along the length of a long-span bridge. Generally, the hanger spacing is similar to or less than the length of a typical HazMat tanker (and thus the fire hazard it creates). Therefore, Hazmat fire is likely to impact multiple hangers. Due to the distinct difference between directly exposed cables, and cables with some longitudinal offset from the fuel fire, more studies on the effects of such offsets on the fire simulation results are deemed necessary. In order to rationally study the temperature results on the cable with different offset distances under a same fire, a fire scenario with multiple hangers with $1 \mathrm{~m}$ spacing is set up to provide enough details (Fig. 10). Five thermocouples are installed evenly on each hanger with $1 \mathrm{~m}$ intervals. The four vertical hangers represent $0,1,2$ and $3 \mathrm{~m}$ longitudinal offsets from the edge of the pool fire.

Results are as expected as shown in Fig. 11: peak exterior temperatures decrease proportionally with longitudinal offset distance for close proximity cables. Correspondingly, the remaining strengths of the hangers increase from $60 \%$ to $80 \%$ with the increase of the longitudinal offset distance at the end of the simulation. It is apparent that the offset is a crucial heating parameter because the maximum temperature decreases sharply at the edge of spill compared to the same trial with the spill centered on the spill. If the cable has a $3 \mathrm{~m}$ longitudinal offset from the edge of the pool fire, less than half of the peak temperature is achieved as compared to the case that a cable is directly engulfed in flames, which leads to $80 \%$ remaining strength after $40 \mathrm{~min}$. These results suggest that the relative location of the HazMat trucks caught in fire to a specific hanger is critical in terms of quantifying the temperature gradient information for that particular hanger. For suspension bridges, multiple hangers may be affected by a 


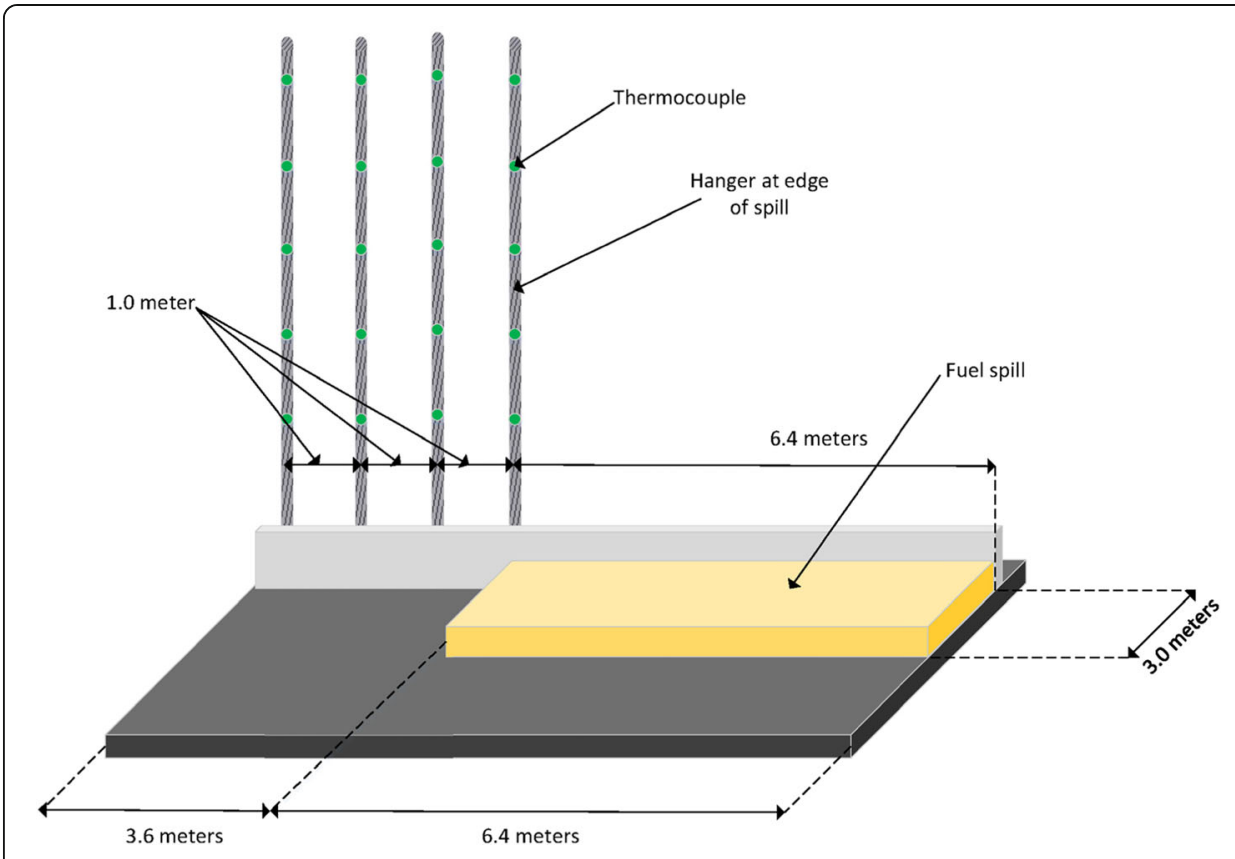

Fig. 10 FDS domain for cable offset investigation

single HazMat fire to different extents due to the fuel pool size and hanger spacing. Therefore, associated progressive failure risks of long-span suspension bridges subjected to damage of multiple hangers under HazMat-caused fire hazards may become considerably large which warrant further and comprehensive assessment.

\subsection{Effect of hazardous material type}

FDS uses input gas species to simulate combustion based on physical and thermal properties of specified species. Because the simple chemistry combustion model is used in FDS with a single type of fuel composed predominantly of oxygen, nitrogen, hydrogen, and carbon, it is not necessary to define all reactants and products in great details.

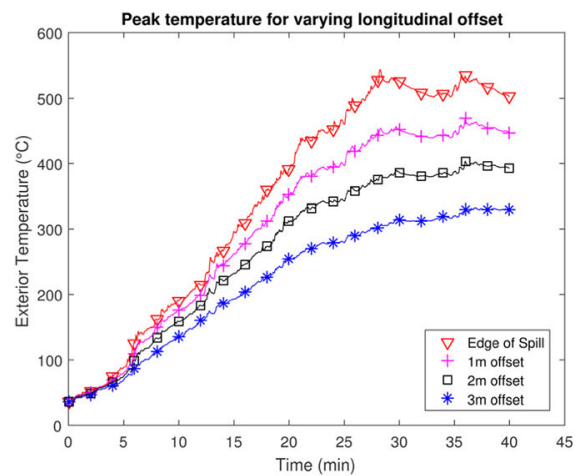

(a)

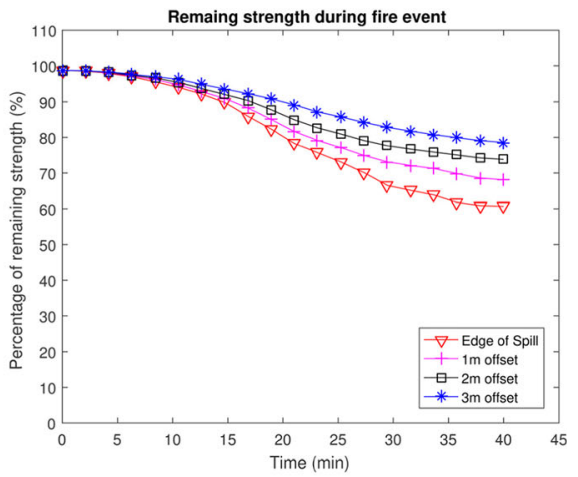

(b)

Fig. 11 Comparison of peak exterior temperatures and remaining strengths of the hangers with different longitudinal offset distances from edge of fire $(10 \mathrm{~m} / \mathrm{s}$ wind speed): a peak exterior temperature; $\mathbf{b}$ percentage of remaining strength based on ASCE code 
The specie n-octane is used as a surrogate for gasoline in most of the simulations. A parametric study is conducted with two other main components of gasoline, butane and toluene and the results are shown in Fig. 12. As seen in Fig. 12 the simulation results (i.e., both peak temperature and remaining strength) of octane and butane are almost identical, while the specie of toluene actually shows significantly higher temperatures than the rest with over $200^{\circ} \mathrm{C}$ higher peak temperatures, which results in as low as $15 \%$ remaining strength after $40 \mathrm{~min}$. Since gasoline is a mixture of the three main components as discussed above, the results shown Fig. 12 can provide bounds and its actual behavior is likely somewhere in-between.

\subsection{Effect of spill size}

To maintain reasonable simulation efforts, all the previous trials were conducted with a spill surface area of approximately $16.2 \mathrm{~m}^{2}$ (5.4 $\mathrm{m}$ width). Depending on the volume of a tanker, the actual spill areas sometimes can be much larger. In this section, the surface area of fuel spill is increased to $27 \mathrm{~m}^{2}$ ( $9 \mathrm{~m}$ width) to examine the effects from the spill size and the results with $10 \mathrm{~m} / \mathrm{s}$ wind speed are shown in Fig. 13. It is found that the spill size can considerably affect the temperature simulation results. For example, the peak temperature can increase over $30 \%$ when the spill longitudinal length is raised from $5.4 \mathrm{~m}$ to $9 \mathrm{~m}$ in width. In addition to the higher peak temperature, the increased spill width also causes the location on the cable experiencing the peak temperature to be closer to the bridge deck than a smaller spill size. In previous trials the peak temperature occurred at 3 or $4 \mathrm{~m}$ above the surface of the spill, while for the larger spill the peak occurred at $2 \mathrm{~m}$ above the spill.

\section{Conclusions}

This study used FDS to simulate the potential heating of exposed hangers due to a hazardous material fire caused by a fuel tanker crash on a suspension bridge. The temperature-independent thermal properties of concrete and steel as well as the combustive properties of gasoline were used to gain a reasonable approximation. For the first time, this study incorporates the wind effect into the fire simulation on long-span

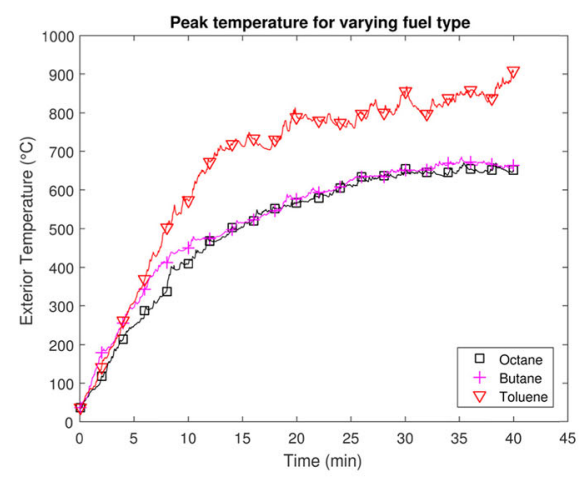

(a)

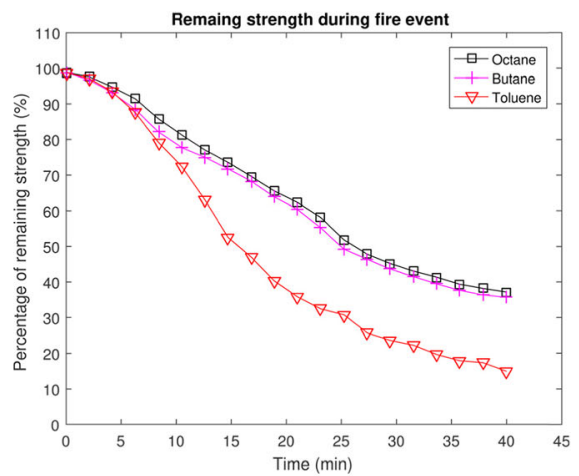

(b)

Fig. 12 Comparison of peak exterior temperatures and remaining strengths of the hanger with different gasoline surrogates ( $10 \mathrm{~m} / \mathrm{s}$ wind speed): a peak exterior temperature; $\mathbf{b}$ percentage of remaining strength based on ASCE code 


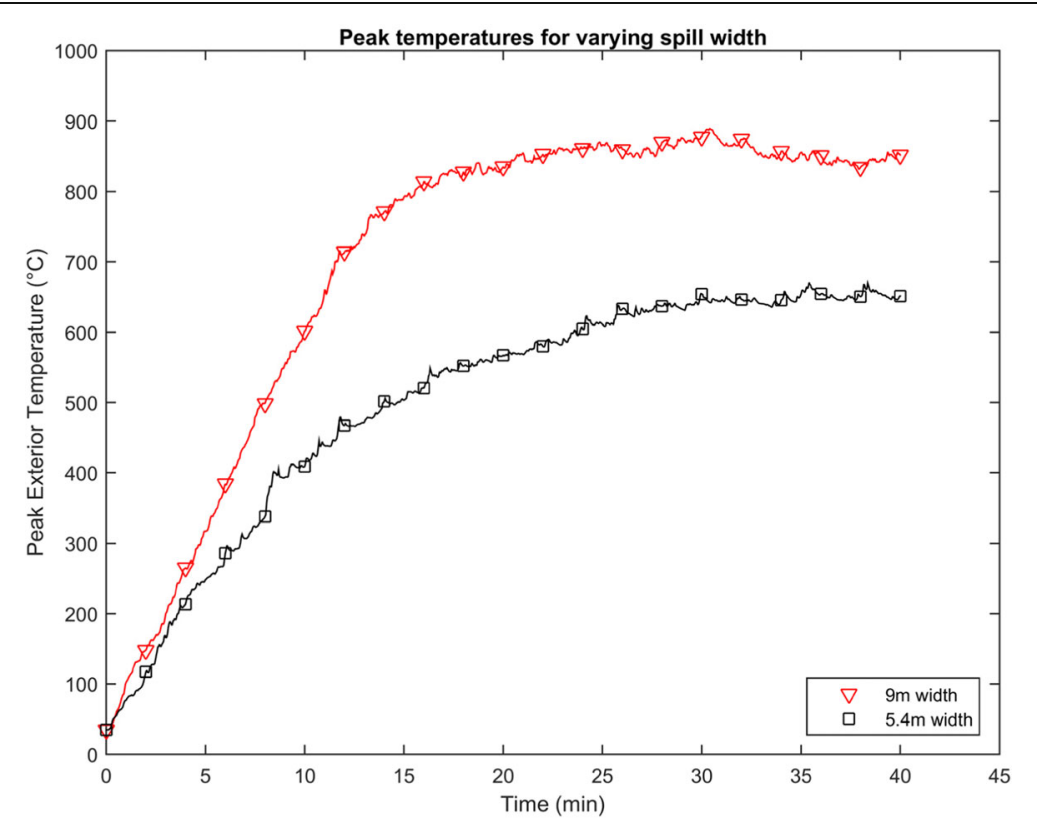

Fig. 13 Comparison of peak exterior temperatures of the hanger with different spill sizes

bridges. Realistic longitudinal offset, spill size and hanger arrangements were considered. Parametric studies further investigated the effects of wind speed, longitudinal offset, spill size and hazardous material type to hanger heating. Additionally, the flame height and temperature-based estimation of strength loss were also presented to help gain perspective on the effects of the fire. The results suggest hanger temperatures are strongly affected by high wind speeds due to the dual effects of increasing fuel mixing and pushing heat towards the hangers. The wind speeds investigated are reasonable approximations of typical wind conditions on the long-span bridge deck. Given the height and open nature of the bridge deck of long-span bridges, much higher wind speeds are very possible and further studies on high wind speeds are deemed essential. Although a detailed structural analysis was not conducted, the preliminary assessment of the strength loss predicted based on the thermal analysis and yield strength-temperature relationships in ASCE guideline and Eurocode shows that the steel hangers may be in danger of losing strength and failing during a typical fire event caused by HazMat accidents.

This study has the following limitations and can be further improved in future work:

1. Finite element analysis can be coupled with the fire simulation to carry out a detailed progressive failure risk assessment to capture the potential risk of fire caused by a HazMat tanker spill.

2. A more advanced CFD-based wind field model can be incorporated to generate turbulent wind flows, leading to more complicated wind-fire interaction scenarios for bridge hangers.

3. Experiments are needed to validate the fire simulation results, including fire characteristics and mechanical properties of steel cables. 


\section{Acknowledgements}

The authors would like to thank the two anonymous reviewers for their many constructive comments and suggestions.

\section{Authors' contributions}

QZ carried out the Abaqus thermal analysis and interpreted the data regarding the FDS fire simulation. KP performed the FDS fire simulation. SC supervised this study and review the manuscript. All authors read and approved the final manuscript.

\section{Funding}

This study is supported by the National Science Foundation (REU supplements) through Grant CMMI-1335571. Any opinions, findings, and conclusions expressed in this material are those of the investigators and do not necessarily reflect the views of the sponsor.

\section{Availability of data and materials}

The datasets used and analyzed during the current study are available from the corresponding author on reasonable request.

\section{Competing interests}

The authors declare that they have no competing interests.

Received: 13 April 2020 Accepted: 26 May 2020

Published online: 07 July 2020

References

"Material properties". (2015) The Engineering Toolbox. http://www.engineeringtoolbox.com/material-properties-t_24.html. Accessed 28 Oct 2015

Alos-Moya J, Paya-Zaforteza I, Garlock MEM, Loma-Ossorio E, Schiffner D, Hospitaler A (2014) Analysis of a bridge failure due to fire using computational fluid dynamics and finite element models. Eng Struct 68:96-110. https://doi.org/10.1016/j. engstruct.2014.02.022

Bennetts I, Moinuddin K (2009) Evaluation of the impact of potential fire scenarios on structural elements of a cable stayed bridge. J Fire Prot Eng 19:85-106. https://doi.org/10.1177/1042391508095091

CEN (European Committee for Standardization) (2005) Design of steel structures, part 1-2 general rules - structural fire design. Eurocode 3, Brussels

Chen C, Chen J, Zhao X, Shi C (2018) Experimental investigation on combustion characteristics of steel cable for cable-stayed bridge. J Therm Anal Calorim 134(3):2317-2327. https://doi.org/10.1007/s10973-018-7689-6

Gong X, Agrawal A (2014) Numerical simulation of fire damage to a long-span truss bridge. J Bridg Eng 20:1-16. https://doi. org/10.1061/(ASCE)BE.1943-5592.0000707

McGrattan K, Hostikka S, McDermott R, Floyd J, Weinschenk C, Overholt K (2015) Fire dynamics simulator users guide (NIST special publication 1019, sixth edition)

Quiel S, Yokoyama T, Bregman L, Mueller K, Marjanishvili S (2015a) A streamlined framework for calculating the response of steel-supported bridges to open-air tanker truck fires. Fire Saf J 73:63-75. https://doi.org/10.1016/j.firesaf.2015.03.004

Quiel S, Yokoyama T, Mueller K, Bregman L, Marjanishvili S (2015b) Mitigating the effects of a tanker truck fire on a cablestayed bridge. International conference on performance-based and life-cycle Struct engineering 1002-1012. https://doi. org/10.14264/uql.2016.539

Sloane M (2017) Fire effects on suspension bridge main cables: methods for determining both temperature and strain distributions within an exposed cable. Doctoral Dissertation. Columbia University

Woodworth M, Hansen E, McArthur C, Abboud N (2015) Protection of cable-stay bridges from accidental and man-made fire hazards: a rational physics based approach to analyzing vulnerabilities and mitigations. ASCE Structures Congress 2015: 24-37. https://doi.org/10.1177/1042391508095091

Wright W, Lattimer B, Woodworth M, Nahid M, Sotelino E (2013) Highway bridge fire Hazard assessment (Transportation Research Board of the National Academies Project no. 12-85). Virginia Polytechnic Institute and State University, Blacksburg, Virginia

\section{Publisher's Note}

Springer Nature remains neutral with regard to jurisdictional claims in published maps and institutional affiliations. 